\title{
An Introductory Business Statistics Course: Evaluating Its Long-term Impact and Suggestions for Its Improvement
}

\author{
Johannes Ledolter \\ Department of Statistics, Vienna University of Economics and Business \\ Administration
}

\begin{abstract}
Undergraduate pre-business students who had taken an introductory business statistics course three years ago were sent a questionnaire that, among several other questions, asked them about their views on the usefulness of the course. Students rated the introductory business statistics course as "moderately important" for their business education. They favored an integrated approach that covers both the statistical concepts and the computer software necessary to carry out the statistical analysis, and they had a strong preference for the Microsoft EXCEL software. Students thought that projects played an important role in introducing them to real-world applications of statistics, but they also mentioned several problems that arose with groupbased work. Factors mentioned as having had an impact on teaching effectiveness are discussed in the last part of the paper.
\end{abstract}

Zusammenfassung: Dieser Artikel beschreibt die Resultate einer Fragebogenuntersuchung zur Evaluierung einer einführenden Statistikvorlesung für Wirtschaftsstudenten. Studentenmeinungen zur Nützlichkeit der Statistikvorlesung wurden drei Jahre nach dem Besuch der Lehrveranstaltung erfaßt. Die Studenten evaluierten die Nützlichkeit der einführenden Statistikvorlesung als "mittelmäßig". Sie bevorzugten eine integrierte Lehrveranstaltung, in der sowohl statistische Konzepte wie auch Computersoftware zur Datenanalyse besprochen werden. Microsoft EXCEL war die bei weitem bevorzugte Computersoftware. Die Studenten bewerteten die Projektarbeit in der einführenden Statistikvorlesung als nützlich, da Projekte einen Einblick in die Anwendungsgebiete der Statistik liefern. Sie erwähnten jedoch auch Schwierigkeiten bei Projekten die in Gruppen ausgeführt werden. Faktoren, die die Wirksamkeit der Vorlesung beeinträchtigen, werden im abschließenden Teil der Arbeit diskutiert.

Keywords: Business Statistics Course; Course Evaluations; Long-term Effectiveness; Project-based Teaching; Teaching Improvements

\section{Background}

There is considerable discussion and controversy on (i) what to teach in an introductory statistics course, and (ii) how to best deliver the material. For an excellent discussion of these issues, see Moore (1997), and papers in The Journal of Statistics Education and the proceedings of annual conferences on How to Make Statistics More Effective in Schools of Business. 
Universities and Colleges in the United States mandate end-of-semester course evaluations for all its courses. There is ample anectodal evidence from instructors of required large-lecture courses with substantial quantitative context arguing that end-of-semester evaluations are not very informative. Critics of end-of-semester evaluations believe that such evaluations do not provide adequate feedback on whether the course communicates the importance of statistics, and they argue that such evaluations focus more on the personality of the instructor, unhappiness with anticipated grades, and complaints about the work load. Critics also suggest that students cannot recognize effective teaching until after being called upon to apply the course materials in downstream courses or as part of job assignments. They argue that if one were to use retrospective (follow-up) ratings from graduates instead of end-of-term assessments from continuing students, student assessment may be different. They reason that follow-up ratings allow former students to develop additional perspectives about, and to obtain emotional distance from, the person and situation being assessed. Such ratings, they argue, have the potential for providing more informative and mature perceptions of course and instructor effectiveness than endof-semester evaluations.

Student ratings of instruction have been the subject of numerous studies. For an excellent overview of findings and unresolved issues, see Marsh (1987) and Schmelkin et al. (1997). Marsh and Overall (1979) and Overall and Marsh (1980) looked at the longterm stability of students' evaluations of instructional effectiveness by studying more than 1,300 undergraduate and graduate business administration majors from 100 different classes who completed their programs at a comprehensive California State University in the mid 1970's. Each student provided course and instructor evaluations at the end of each class, as well as one year after graduation from the program (that is, 1-3 years after having taken any course). Fifty-five percent of the students completed both surveys. The study provided support for the stability of students' evaluations of their courses and instructors, and it suggested that this stability does not vary systematically with course level or context. According to the results of their study, students did not change their initial evaluative judgments.

Little is known about the long-term impact of individual college courses, and even less is known about the introductory statistics course. Statistics usually is taught early in the program, before students have taken course work in their substantive areas. Thus, it is of interest to study whether students change their assessment of statistics after having developed additional perspectives about their field of study.

\section{The Course}

When I was a faculty member at the University of Iowa I conducted a three-year followup survey of former students in the introductory business statistics course which I had taught in the spring semester of 1994. The business statistics course at the University of Iowa, offered by the Department of Statistics and Actuarial Science, is the second in a three-course sequence for pre-business/business students. The sequence starts with Quantitative Methods I, a review of mathematics for business students. This is followed by the introductory business statistics course, Quantitative Methods II, the topic of this 
paper. The grades in these two courses are important for admission to the undergraduate business degree programs, as students need at least a $C$ in each of these courses. The threecourse sequence concludes with a second business statistics course, Statistical Analysis, which builds upon the introductory course. All three courses are required for business majors at the University of Iowa.

The University of Iowa uses a large-lecture format for its introductory business statistics course, with three weekly lectures given by the faculty member in charge of the course, and two weekly hours of computer and discussion sessions in groups of about 25 students; the discussion sessions are directed by teaching assistants. The purpose of the business statistics course is to give students an introduction to useful statistical techniques. When I taught this course in the spring semester of 1994, I discussed data plots, descriptive statistics, measures of association among categorical and continuous variables, the normal and binomial probability distributions, data collection and sampling schemes, data modeling, control charts, statistical inference (including confidence intervals, test statistics and probability values), and regression analysis. Cryer and Miller, Statistics for Business: Data Analysis and Modeling (2nd edition, Duxbury Press, 1994), was used as the required text book; Chapters 1 through 17 were covered.

An important objective of this course was to convey to students the utility and importance of statistics, and to teach them how to implement basic statistical techniques in the context of real data analysis. The MINITAB computer software was an integral part of the course. The course combined the discussion of statistical concepts and the computer software needed to carry out the data analysis.

An important component of my course was a project where students applied the studied statistical techniques to a real-world problem. The project was carried out in groups of 4-5 students, selected at random from the same discussion group. The group was responsible for formulating the project, collecting the appropriate data, running the required analyses, and summarizing the findings. The grade on the project had an important effect on the final grade as the project carried the same weight as a comprehensive final examination and twice as much as a midterm examination. Each member of the group was awarded the same number of points. For a detailed description on the use of projects in introductory statistics courses, see Ledolter (1995).

I believe that my course was consistent with the recommendations of experts on the teaching of statistics. The ASA/MAA Joint Committee on Undergraduate Statistics (see Cobb (1992)) made three basic recommendations for courses whose goal is to introduce the nature of statistics to beginning students:

1. Emphasize the elements of statistical thinking including the need for data, the importance of data production, the omnipresence of variation, and the measuring and modeling of variation.

2. Incorporate more data and concepts, fewer recipes and derivations. Wherever possible, automate computations and graphics. Rely on real data and computers, emphasize statistical concepts, and treat formal derivations as secondary in importance.

3. Foster active learning, through the following alternatives to lecturing such as group problem solving, laboratory exercises, demonstrations based on class-generated data, written and oral presentations, and projects (either group or individual). 


\section{The Survey}

The introductory business statistics course of Spring 1994 started with more than 500 students, but due to drop-outs only 450 received a final grade. I could not locate the addresses of eleven students. The remaining 439 students were sent a copy of the course syllabus, an accompanying letter describing the objectives of the survey, and a questionnaire. The questionnaire and the accompanying letter are included in the appendix. The survey was sent out in early June of 1997, and students were asked to respond by September 15, 1997. Surveys were sent to the student's home address as it was thought that students would either live at home during the summer, visit home during the summer, or get mail forwarded to their current address. An addressed, stamped envelope was included for the return. Questionnaires were numbered and coded for two reasons: (i) I anticipated a low response rate and wanted to sample non-respondents. (ii) I wanted to incorporate into the analysis the demographic information and the final grade that students received in this course.

The survey tried to address several areas:

- How do students view the introductory business statistics three years after they have taken the course? Has time changed their assessment of the course? What has been the long-term impact of the course?

- Has the course project been successful? Did the projects contribute to an appreciation of statistics? How do students feel about carrying out projects in groups where each group member is awarded the same number of points?

- Which topics of the introductory business statistics turned out to be the most useful in down-stream courses? Which topics turned out useful in job-related applications?

- How do students view the integration of statistical concepts with hands-on computer analysis? How do students view the usefulness of MINITAB?

\section{The Survey Results}

Only sixty-five of 439 students responded, for a response rate of 15 percent. The response rate was disappointingly low; considerably lower that the 55 percent response rate in Marsh and Overall (1979). The follow-up of 35 randomly selected non-respondents did not fare much better; only six students, or 17 percent, responded to the second letter. The low response rate is troubling, but realistically one may not be able to expect much more from a mail survey without incentives to respond. Telephone surveys would have been preferable, but a list of telephone numbers was not available nor did I have the resources to make the calls. Conclusions from a volunteer survey with a low response are limited. Statistical significance tests based on such sample results are certainly not meaningful as the sample is not random; for this reason significance levels are omitted throughout the paper. Despite these problems, survey results are of value as they point out tendencies and problem areas. 
The low response rate was surprising as I thought that students would be eager to help improve the course. One does not know for sure why students failed to respond. The letter may not have reached them, they may have forgotten to respond, or after three years they simply may not have cared. In order to assess the representativeness of the sample and to learn more about who had responded and who didn't, I compare in Table 1 demographic characteristics of the population (that is, the 439 students who were sent the survey) with those of responding students. There are few differences with respect to gender and class standing. However, there is evidence that the response rate of students who received a good grade (A or B) is somewhat larger than the one of students with a grade of $\mathrm{C}$ or worse. Forty-two percent of students received a course grade $\mathrm{C}$ or worse, but only 29 percent of the respondents came from that group.

Table 1: Comparison of gender, class standing, and course grade characteristics in the population (439) and the sample (65 respondents)

\begin{tabular}{lccccccccccc} 
& \multicolumn{4}{c}{ Gender } & \multicolumn{4}{c}{ Class Standing } & \multicolumn{4}{c}{ Course Grade } \\
& Female & Male & Fr & So & Ju & Se & A & B & C & D & F \\
\hline & & & & & & & & & & & \\
Population & 35.6 & 64.4 & 52.4 & 28.6 & 15.3 & 3.7 & 17.0 & 40.6 & 33.9 & 5.7 & 2.8 \\
Sample & 38.5 & 61.5 & 53.8 & 29.2 & 13.9 & 3.1 & 23.1 & 47.7 & 23.1 & 6.1 & 0.0 \\
\hline
\end{tabular}

\section{Question 1: Importance of Quant II topics for subsequent course work}

On a scale from 1 (not at all important) to 5 (extremely important), the average score on question 1 was 2.98. This implies "moderate importance" of the topics in Quant II for students' subsequent course work. Table 2 stratifies the results according to gender, class standing, and earned course grade. There are some differences according to gender; male respondents rate the course topics more important. Ratings are similar across class standing and course grades.

Analysis of topics students found most useful in their subsequent courses revealed the following results. The most frequently mentioned topics, in order of decreasing importance, were: descriptive statistics (mentioned 14 times), distributions (13 times), survey sampling (11 times), regression (10 times), and control charts (7 times). Students commented on the importance of survey sampling in accounting (auditing) courses, of regression in finance courses, and of control charts in courses on operations management.

\section{Question 2: Importance of Quant II topics in the context of a job assignment}

Thirteen of the 65 respondents ( 20 percent) had no job experience and skipped this question. The remaining 52 students ranked the importance of the introductory business statistics course as 2.25, on a five-point scale from 1 (not at all important) to 5 (extremely important); this puts the course just below the "moderately important" category. According to the students, its impact on the business world is less than its importance for subsequent course work (with average rank on question 1 as 2.98). Students listed sample surveys, descriptive statistics, and regression as the most useful areas. 
Table 2: Average scores on Question 1

\begin{tabular}{lll} 
& Average & StdErr \\
\hline $\begin{array}{l}\text { Overall Score: } \\
\text { Gender: }\end{array}$ & 2.98 & 0.14 \\
Female & & \\
Male & 2.52 & 0.22 \\
Class Standing: & 3.28 & 0.16 \\
Freshman & & \\
Sophomore & 3.03 & 0.19 \\
Junior & 3.05 & 0.24 \\
Senior & 2.78 & 0.40 \\
Course Grade: & 2.50 & $(\mathrm{n}=2)$ \\
A & & \\
B & 2.93 & 0.27 \\
C & 3.06 & 0.20 \\
D & 2.93 & 0.33 \\
& 2.75 & $(\mathrm{n}=4)$ \\
\hline
\end{tabular}

The low assessment on question 2 was surprising. However, this may not necessarily imply that statistics is not used in the business world; it may just show that students did not encounter work-related problems that could be addressed by statistical tools.

\section{Question 3: The role of the project in introducing students to real-world applications of statistics}

Students thought that the project played a role in introducing students to real-world applications of statistics. The average score on question 3 was 2.98, on a five-point scale with 1 (not at all) to 5 (extremely well). Table 3 shows that the course grade had some effect on how students viewed the importance of the project. Students with good grades evaluated the importance of the project more favorably than students with bad grades.

Table 3: Results on Question 3

\begin{tabular}{|c|c|c|}
\hline & Average & StdErr \\
\hline $\begin{array}{l}\text { Overall Score: } \\
\text { Course Grade: }\end{array}$ & 2.98 & 0.16 \\
\hline A & 3.20 & 0.35 \\
\hline B & 3.20 & 0.23 \\
\hline C & 2.60 & 0.32 \\
\hline D & 2.20 & $(n=2)$ \\
\hline
\end{tabular}

\section{Question 4: The group-aspects of the project}

Twenty of 65 students, or 31 percent, said that the group aspect of the project helped them in their subsequent course work. Experiences with the group aspect of the project were similar across the various groups of gender, class standing and course grade. Thirty-one of 65 students, or 48 percent, evaluated the group-experience as mostly good; twenty of 65, 
or 31 percent, thought that the experience was mixed, while fourteen of 65 , or 22 percent, classified their experiences as bad. The detailed comments on this question revealed that the most common problem with groups was a lack of participation and accountability of some group members. Students commented that it would be better to have several small and well-defined tasks instead of a single comprehensive project. Students also wished for more involvement of the teaching assistants and for more frequent check points of their work.

\section{Question 5: Statistical computer software}

There was overwhelming support for covering both the statistical concepts and the statistical software necessary to carry out the analysis. Only seven of 65 students, or 11 percent, objected to having both topics taught in the same course. There were no appreciable differences in the responses across the categories of gender, class standing, and course grade. Only five of 65 students, or 7.7 percent, indicated that they continued to use MINITAB beyond the Quant II course. Almost every respondent used EXCEL in their subsequent business courses.

\section{Question 6: Additional topics that should be covered in Quant II}

Fifty-nine of 65 students, or 91 percent, offered no suggestion on what other statistical topics they would like to have seen in Quant II. Only six students listed topics, and most suggestions had to do with advanced regression. The lack of response to question 6 was disappointing, as one would have thought that the undergraduate business curriculum would have exposed students to more advanced statistics concepts.

\section{Question 7: Students' current assessment of Quant II}

I wondered whether student assessments of the introductory statistics course had changed over time. I hoped that students would realize the importance of statistics as they proceed through the business curriculum. The introductory business statistics course comes very early in the program-at a time when students have little business background. At that time students view the statistics course as a necessary evil and not as something that can help them. I hoped that through time and exposure to business topics, students would gain appreciation for statistics.

On average, the rating of the statistics course after three years time was somewhat better than the end-of-semester evaluation. Among the 71 percent (46 of 65) of students who indicated that they could recall their earlier assessment, the average score on question 7 was 3.22; again on a five-point scale where 3 refers to "about the same" and 4 to "somewhat better." The results in Table 4 show that students with a good course grade tended to revise their assessment upwards, while students with low grades revised their assessment downwards.

Table 4 also relates the responses on question 7 to the ratings students gave to the importance of Quant II for their subsequent course work (question 2). It shows that students who believed that statistics was important tended to raise their assessments.

\section{Question 8: Grades in Quant II}

I included a question that allowed for a check whether students actually remembered their grade. The results show that, while students may not remember many details of the 
Table 4: Summary statistics for Question 7:

\begin{tabular}{lcc} 
& Average & StdErr \\
\hline $\begin{array}{l}\text { Overall Score: } \\
\text { Gender: }\end{array}$ & 3.22 & 0.15 \\
Female & 3.31 & 0.24 \\
Male & 3.17 & 0.19 \\
Course Grade: & & \\
A & 3.55 & 0.21 \\
B & 3.45 & 0.14 \\
C & 2.50 & 0.40 \\
D & 2.50 & $(\mathrm{n}=4)$ \\
Importance of Quant II & & \\
for subsequent course work: & & \\
1 (not at all important) & 2.00 & 0.45 \\
2 (moderately important) & 3.00 & 0.30 \\
4 and 5 (extremely important) & 3.38 & 0.27 \\
\hline
\end{tabular}

course, they definitely remember their grades. Only six of 65 students could not recall their grade. Students who claimed to remember their grade recalled their grades quite accurately; see Table 5.

Table 5: Cross tabulation of frequencies for recorded grade (rows) and recalled grade (columns)

\begin{tabular}{cccccc} 
& & \multicolumn{4}{c}{ Recalled Grade } \\
Recorded Grade & Didn't recall & A & B & C & D \\
\hline A & 0 & 14 & 1 & 0 & 0 \\
B & 3 & 1 & 25 & 1 & 1 \\
C & 1 & 0 & 4 & 10 & 0 \\
D & 2 & 0 & 0 & 0 & 2 \\
\hline
\end{tabular}

\section{Question 10: Suggestions that could improve Quant II}

Suggestions, ordered according to decreasing frequencies with which they were mentioned, were: Making the statistics course more relevant to real-world business issues; changing the large-lecture format of the introductory business statistics course to smaller more interactive sections; establishing safeguards that prevent fellow students from cheating on exams and free loading on projects; switching to a different computer software, namely EXCEL; using a different text book; and using a different instructor and teaching assistants.

\section{Question 11: Comments on the statistics education at the University of Iowa}

In general, students were quite satisfied with their statistics courses at Iowa. Positive comments outnumbered negative ones by a margin of 3 to 1 . Suggestions included more 
interactive ways of presenting the material, better coordination with other lectures, and more orientation of the statistics courses to real-life issues.

\section{Discussion of Results}

Factors that impact the effectiveness of the currently-used teaching approach and improvement opportunities are reviewed in the final section of this paper. This discussion uses results of the survey, but also draws on personal observations that I made while teaching introductory statistics courses.

\section{Importance of grades, cheating and plagiarism}

Grades in the introductory business statistics course are very important as they determine whether a student will be admitted to the College of Business. One could say that the business statistics course serves to "weed out" the crop of pre-business students. This puts statistics into an undesirable position, as it is perceived as a hurdle and not as an opportunity.

Emphasis on grades also encourages cheating and free-loading on group projects as was pointed out in the comments to question 4. In a large-lecture course where the instructor supervises more than one-hundred projects it is difficult to control free-loading as one has to rely on the honesty of students. Cheating is also difficult to eliminate as definitions of what constitutes plagiarism are often ambiguous and poorly understood. It is therefore important to establish clear guidelines for ethical conduct and to enforce strict penalties for cheating; otherwise, the integrity of grades will be undermined.

\section{Insufficient business background: Do we expect too much?}

We have changed the nature of the introductory business statistics course by making statistics more relevant to business. However, I found that freshman and sophomore students in this course have very little background of business and management. They haven't yet learned about business by the time they attend the business statistics course. They have great difficulties to find business-related projects and they often resort to project topics that have to do with sports.

\section{The drawback of large lecture courses}

We spend much time on the preparation of lectures and lecture materials. However, good lectures are only one entry point to understanding, and we often forget that learning requires two-way communication. In large-lecture courses there is the definite danger that two-way communication fails to take place. Large lecture-courses limit the time a professor can spend with each student. But more importantly, students in such courses are reluctant to speak up and seek out the help of professors. Small(er) courses should be more successful.

\section{Problems with the evaluation of group-based work}

Most freshman and sophomore students do not know how to work in groups. It is only later in their course work that they learn about teams and shared responsibilities. The group-based projects are their first practical exposure to team work; and in some sense 
they get exposed to it without much training and preparation. Being able to work in groups is very important in business, but at the undergraduate level very little is done to teach how this can be achieved. More instruction on effective teamwork is needed.

\section{Large projects or smaller group-based activities}

A difficulty with my statistics course is that it puts great emphasis on a project for which it is necessary to translate quantitative information into words. The comments on question 4 show that many students feel that a comprehensive and unstructured project was too challenging. Students gave the following reasons: (i) It is difficult to find a topic with a reasonably large scope, but not too large so that one cannot finish the work. (ii) Students delay the project until late in the semester, and then they are rushed to finish the work. (iii) Since projects are carried out in groups, students have great difficulties in dealing with their sometimes immature fellow colleagues. It is difficult for them to arrange group meetings on a continual basis.

A large project is also a test of students' managerial skills. For many students the project is their first experience with project management-a topic that is discussed in management courses later in their business program. I believe that the managerial aspects of the project (that is team-work and project management) and the writing experience are very beneficial. However, I also understand that these aspects put additional burden on the students as the introductory business statistics course now involves more than just learning statistics. The comments to question 4 of the survey imply that students prefer the assignment of more narrowly-defined activities that they can finish within a shorter time period.

\section{Statistical computer software}

Almost all students remarked that they had not used MINITAB since taking the introductory business statistics course, and they wondered why we didn't use EXCEL, the commonly-used business software. MINITAB is an excellent package-statistically correct, and easy to learn and use. However, the students have a good point. What good is it to teach a software package which only few will use in the future? EXCEL, while not perfect as a statistical package, has improved over the years and with the many currently available add-ins it has become a powerful package. I believe that we have reached a point where we can safely switch to EXCEL. I use EXCEL in MBA and Executive MBA business statistics courses. Students in these courses are already familiar with the Microsoft Office products, and it takes little time to explain EXCEL. The time saved can be used to point out and correct problems in EXCEL.

\section{Relevance of this study for the Austrian university system}

This survey was designed for an U.S. undergraduate business statistics course, and not all findings in this paper may be relevant for the Austrian system of university instruction. However, several aspects are of importance: (1) Austrian universities have not had a tradition of regular course evaluation by students. However, the evaluation of university instruction will become increasingly important, and so will be the course evaluations which are described in this paper. (2) The teaching of introductory statistics is challenging within all systems. It is important to find the right mix of theory and applications, of individual and group work, of rote practice and interesting projects. And, to achieve all 
this with students who are afraid of statistics and who-by virtue of the early scheduling of the statistics course-are not familiar with business and management issues.

\section{References}

G.W. Cobb. Teaching statistics. L.A. Steen, (editor): Heeding the Call for Change: Suggestions for Curricula Action. Washington, D.C.: Mathematical Association of America, pages 3-43, 1992.

J. Ledolter. Projects in introductory statistics courses. The American Statistician, 49: 364-367, 1995.

H.W. Marsh. Students' evaluations of university teaching: Research findings, methodological issues, and directions for future research. International Journal of Educational Research, 11:253-388, 1987.

H.W. Marsh and J.U. Overall. Long-term stability of students' evaluations: A note on Feldman's consistency and variability among college students in rating their teachers and courses. Research in Higher Education, 10:139-147, 1979.

D.S. Moore. New pedagogy and new content: The case of statistics. International Statistical Review, 65:123-165 (with discussion), 1997.

J.U. Overall and H.W. Marsh. Students' evaluations of instruction: A longitudinal study of their stability. Journal of Educational Psychology, 72:321-325, 1980.

L.P. Schmelkin, K.J. Spencer, and E.S. Gellman. Faculty perspectives on course and teacher evaluations. Research in Higher Education, 38:575-592, 1997.

Author's address:

Univ.-Prof. Dr. Johannes Ledolter

Institut für Statistik

Abteilung für mathematische Methoden der Statistik

Wirtschaftsuniversität Wien

Augasse 2-6

A-1090 Wien

Tel.: +43131336/4756

Fax: +43 $131336 / 774$

Email: Johannes.Ledolter@wu-wien.ac.at

http://www.wu-wien.ac.at/wwwu/institute/stat1/tafel1.html 


\section{Appendix 1: Letter to students}

Iowa City, June 1997

Dear former student of Quant II:

More than three years ago, you finished my course Quantitative Methods II, also known as 22S:8. This course is offered by the Statistics Department as a required course for business majors at the University of Iowa. In order to refresh your memory, I have enclosed a copy of the syllabus.

The purpose of this course was to give you an introduction to statistical techniques and quantitative problem solving tools. You learned about statistical techniques in the context of real data analysis, and we studied how to recognize and remedy defects in statistical analysis.

We discussed such topics as data plots, descriptive statistics, associations among variables, data modelling, control charts, probability distributions, data collection, sampling strategies, statistical inference, and regression.

The main goal with of this course was to introduce you to the utility of statistics and to show you the importance of sound statistical methods for decision making. Knowing how to applying basic statistical techniques within the context of real data analysis was an important objective.

We used MINITAB as the computer software for the statistical analyses.

You may remember that a project was an important component of the course, and also of your grade. The project was carried out in groups of 4-5 students. For your project I asked you to apply one or more of the studied statistical techniques to a real-world problem. You were responsible for formulating the project, collecting the appropriate data, running the required analyses, and summarizing the findings. A goal of the project was to get you involved in a real-world application of statistics.

There is much discussion on how to teach introductory statistics to business students, and there are differing opinions on topics to be included, the role of computers, and the importance of projects with data analysis and writing emphasis. I would like to obtain some data on how the Quant II course has worked for you. The university collects end-of-the-semester evaluations on a routine basis. However, we have no information on how our courses contribute to student's understanding of subsequent courses, and how valuable they are for you further down the road.

I would be grateful if you could return the brief survey by September 15, 1997. However, later returns are always appreciated as your comments will help us improve our courses in the future. Thank you for your feedback. Let me assure you that your feedback will be treated confidentially; only summary statistics will be made available.

Sincerely yours

Johannes Ledolter

Professor, Department of Statistics and Actuarial Science 


\section{Appendix 2: Quantitative Methods II (22S:8)-The Questionnaire}

1. In Quant II we covered data plots, descriptive statistics, associations among variables, data modeling, control charts, probability distributions, data collection, sampling strategies, statistical inference, and an introduction to regression.

How important were the topics that you learned in Quant II for your subsequent course work?

$$
\begin{array}{cccc}
1 & 2 & 3 & 5 \\
\text { Not at all important } & & \text { Moderately important } & \text { Extremely important }
\end{array}
$$

Please list the Quant II topics that you found the most useful and tell me how you have used them.

2. How important were the topics that you learned in Quant II for solving problems that came up in the context of a job assignment?

- Not applicable as I have no job experience
1
2
3
4
5
Not at all important Moderately important Extremely important

Please list the Quant II topics that you found the most useful and tell me how you have used them.

3. The project: Do you believe that the project in Quant II served its role in introducing you to a

\begin{tabular}{|c|c|c|c|}
\hline 1 & 2 & 3 & 4 \\
\hline Not at all & & To some degree & \\
\hline
\end{tabular}
real-world application of statistics?

Comment on how one could improve the project component of Quant II:

4. The group-aspect of the project:

Evaluate your experiences with the group-aspect of your Quant II project. The experience was

- Mostly bad - About equal parts good and bad - Mostly good

Did the group-experience in carrying out the Quant II project help you in your further courses?

- Yes - No

Comment on how one could improve work in groups:

5. Statistical computer software: The Quant II course emphasized the use of a statistical software package (MINITAB). Do you believe that it is a good idea to teach both statistical concepts and a statistical software package in the same introductory course?

- Bad idea to include both in the same course

- Indifferent

- Good idea to include both

In Quant II we used MINITAB as the computer software. Have you used MINITAB in other courses?

- Yes - No

If you haven't used MINITAB, what other software packages (for example EXCEL, STATA, SAS, SPSS, .... ) have you used? 
6. In Quant II we covered data plots, descriptive statistics, associations among variables, data modelling, control charts, probability distributions, data collection, sampling strategies, statistical inference, and an introduction to regression. What other topics (beyond those covered in Quant II) would you have liked to have seen?

- Not sure

- Please list topics

7. Compare your current assessment of Quant II with your end-of-semester course evaluation. My current assessment of Quant II is

- Don't recall

- Considerably worse than the end-of-semester evaluation

- Somewhat worse

- About the same

- Somewhat better

- Considerable better than the end-of semester evaluation

8. What was your grade in Quant II?

- Don't recall

- Specify grade

9. Your career aspirations: Have you obtained, or are you in the process of obtaining a Business undergraduate degree?

- Yes

- No, switched my major to

- Dropped out of school

For those who are still enrolled as undergraduates:

Please specify your employment plans after graduation:

For those who have graduated with an undergraduate degree:

Please specify your current job assignment:

10. Please add suggestions that could improve the Quant II course:

11. Please add any comments that you may have regarding your statistics education at the University Iowa.

Please use an extra sheet if you have further detailed comments. We welcome your input! Thank you for your time. 